\title{
Cardiovascular Autonomic Function in Individuals with Rheumatoid Arthritis
}

\author{
Dr. Pranjali Deshpande ${ }^{1}$, Dr. Deepak S. Howale ${ }^{2}$ \\ ${ }^{1}$ Associate Professor Dept. of Physiology Zydus Medical College and Hospital, Dahod \\ ${ }^{2}$ Dean Govt. Medical College, Silvassa
}

\begin{abstract}
Rheumatoid arthritis is common inflammatory arthritis arising throughout the world. A chronic systemic inflammatory autoimmune disorder is known as Rheumatoid arthritis (RA). Principally it affects the joints and usually accompanied by one or more of extra-articular manifestations as rheumatoid nodules, neuropathy and norm chromic normocytic anemia. Rheumatoid arthritis can start at any age, but has maximum between 35 to 55 years of age. The prevalence of RA is about $1 \%$ worldwide whereas India is $0.9 \%$ with women suffering 3-5 times more than men. Sympathetic and parasympathetic involvement has described in primary and secondary vasculitis processes, as in systemic vasculitis processes like: SLE, RA. Peripheral nervous system is the main target in RA patients where as involvement of central nervous system (CNS) is rare. The aim of this study was to evaluate cardiac autonomic function in RA and compare with healthy individuals by using HRT analysis. Materials and Methods: A cross-sectional study was performed which was carried out in the Dept. of Physiology at Zydus Medical College and Hospital. It was carried out on both males and females of mean age group $45 \pm 10$ years to study autonomic functions in RA. Total 50 individuals were include in which 25 were included as healthy individuals with not on any medication, served as controls and 25 were diagnosed with RA, on the basis of criteria developed by American College of Rheumatology along with sex matched controls. Details of history and examination were recorded on Performa. Patients were examined for signs and symptoms of possible Autonomic Nervous System (ANS) dysfunctions. Result: 50 individuals were include in this study which were grouped into Study group (Group - A) and Control group (Group - B). Group - A consisted of 25 individuals who were diagnosed with rheumatoid arthritis on basis of criteria developed by American College of Rheumatology. Group B consisted of 25 healthy individuals not on any medication as to explain normal changes. The 30:15 ratio and valsalva maneuver demonstrated a less decrease but was non-significant statistically in the patients with Rheumatoid Arthritis as compared to control ( $p>0.05$ ). On standing the blood pressure response the change in diastolic blood pressure was significantly $(\mathrm{P}<0.01)$ lower in groups A as compared to control. Conclusion: Cardiovascular autonomic function tests in routine clinical examination helpful in early detection of autonomic dysfunction in this disease. Further comprehensive information are useful about autonomic function may be extracted from global evaluation of all tests performed. Therefore testing of autonomic function may be the part of routine clinical evaluation in RA to reduce the cardiovascular autonomic morbidity.
\end{abstract}

Keywords: Cardiovascular, Rheumatoid Arthritis (RA), ANS dysfunction

\section{Introduction}

Rheumatoid arthritis is common inflammatory arthritis arising throughout the world. ${ }^{[2]}$ A chronic systemic inflammatory autoimmune disorder is known as Rheumatoid arthritis (RA). Principally it affects the joints and usually accompanied by one or more of extra-articular manifestations as rheumatoid nodules, neuropathy and normochromic normocytic anemia ${ }^{[3,4]}$ such as weight loss, anemia, rheumatoid nodules, rheumatoid vasculitis, etc. Rheumatoid arthritis can start at any age, but has maximum between 35 to 55 years of age. ${ }^{[5]}$ The prevalence of RA is about $1 \%$ worldwide whereas India is $0.9 \%$ with women suffering 3-5 times more than men. ${ }^{[6]}$ The affection of the sympathetic and/or parasympathetic nerve fibers causes Autonomic neuropathy which clinically manifests as clammy, cold, palpitation, cyanotic extremities, peripheral vasospasm, syncopal attacks, orthostatic hypotension and sexual dysfunction. ${ }^{[7,8]}$ Sympathetic and parasympathetic involvement has described in primary and secondary vasculitis processes, as in systemic vasculitis processes like: SLE, RA. ${ }^{[9]}$ According to studies on western population, activity of sympathetic nervous system is significantly elevated in RA patients. ${ }^{[10]}$ Peripheral nervous system is the main target in RA patients where as involvement of central nervous system (CNS) is rare. Although in RA patients' cardiac involvement is not always symptomatic, it has shown, due to cardiovascular events there was a significantly increased mortality ratio ${ }^{[11,12,13]}$ In 1999 Louthrenoo W, Ruttanaupawan et al showed $47 \%$ of RA patients had symptoms suggesting ANS dysfunction without any correlation with disease duration, or raised ESR. ${ }^{[14]}$ The aim of this study was to evaluate cardiac autonomic function in RA and compare with healthy individuals by using HRT analysis.

\section{Materials and Methods}

A cross-sectional study was performed which was carried out in the Dept. of Physiology at Zydus Medical College and Hospital. It was carried out on both males and females of mean age group $45 \pm 10$ years to study autonomic functions in RA. Total 50 individuals were include in which 25 were included as healthy individuals with not on any medication, served as controls and 25 were diagnosed with RA, on the basis of criteria developed by American College of Rheumatology[15] along with sex matched controls. The procedures were in accordance with the ethical standards of the committee of the institute. Special care was taken 


\section{International Journal of Innovative Research in Medical Science (IJIRMS) Volume 03 Issue 12 Dec 2018, ISSN: 2455-8737, Imp. Factor - 4.102 \\ Available online at - www. ijirms.in}

so that any relevant history will not miss. Details of history and examination were recorded on Performa. Patients were examined for signs and symptoms of possible Autonomic Nervous System (ANS) dysfunctions including orthostatic hypotension (blurred vision, sensation of weakness and unsteadiness, light headedness, fainting or syncope on standing), perspiration, palpitations and Raynaud's phenomenon. The written consent of subjects was taken on inform consent form in local language.

CRITERIA FOR EVALUATION: To evaluate cardiac Parasympathetic nervous system functions following tests were performed:

\section{Heart rate response to standing (30:15 Ratio):}

Individuals was ask to lie comfortably and ECG was recorded in lead II continuously on cardio fax for $30 \mathrm{sec}$, then asked to stand up unaided, the point when the patient standing was marked on ECG. The ECG was recorded for 1 minute from standing. with a help of ruler the R-R intervals were measured on ECG. The 30:15 ratios was calculated by taking ratio of longest $R R$ interval at beat 30 and shortest R-R interval at beat 15 after standing. A 30:15 ratio of 1.00 was taken as normal and value of $<1.00$ was considered abnormal. ${ }^{[16]}$

$$
\text { 30: } 15 \text { ratio }=\frac{R-R \text { interval at beat } 30}{R \text { ? } R \text { interval at beat } 15}
$$

\section{Heart rate response to lying down (Standing / Lying Ratio):} Individual was asked to stand quietly; then lie down without any support while continuous ECG was recorded from 20 beats before to 60 beats after lying down. The point at which individual started to lie down was marked. S/L ratio was calculated as longest R-R interval during 5 beats before lying down to shortest R-R interval during 10 beats after lying down ${ }^{[17]} \mathrm{S} / \mathrm{L}$ is test for parasympathetic damage. An S/L ratio of $>1$ was taken as abnormal. An S/L ratio of $<1$ was taken abnormal. ${ }^{[18]}$

$$
S / L \text { ratio }=\frac{\text { Longest } R R \text { interval during } 5 \text { beats before lyingdown }}{\text { Shortest } R-R \text { interval during } 10 \text { beats after lyingdown }}
$$

\section{Heart Rate variation during deep breathing}

\section{(Expiration/inspiration Ratio):}

Individual was asked to breathe deeply at rate of six breaths per minute. During deep inspiration and expiration a standard ECG recording was recorded. Variation in heart rate was calculated as ratio of longest $\mathrm{R}-\mathrm{R}$ interval during expiration to shortest $\mathrm{R}-\mathrm{R}$ interval during inspiration. ${ }^{[19]}$ A value of 1.20 or higher was taken as normal. ${ }^{[20]}$

$$
\text { Expiration/Inspiration ratio }=\frac{\text { Longest } R-R \text { interval during expiration }}{\text { Shortest } R-R \text { interval during inspiration }}
$$

For evaluation of cardiac sympathetic nervous system functions following tests were performed:

\section{B.P response to Standing}

Individual was asked to stand and remain motionless from supine position within 3-4 sec. Blood pressure was recorded in 30 second interval. Difference between SBP recorded in lying position and then after standing was calculated. Normal response is taken as 20$30 \mathrm{~mm} \mathrm{Hg}$ of systolic and $>20 \mathrm{~mm} \mathrm{Hg}$ diastolic (AAS \& AAN, 1996) is taken abnormal. ${ }^{[21]}$

\section{B.P response to Valsalva maneuver (VM ratio)}

\section{B.P response to sustained hand grip}

Details of procedure were explained and baseline BP was recorded with the help of sphygmomanometer. The individual was asked to hold the hand grip dynamometer in right hand and was instructed to compress the hands with maximum effort. The tension developed was measured, 3 readings were taken and mean of three readings was taken as Tmaxmaximal isometric tension. ${ }^{[22]}$ The diastole BP rise at the point just before the release of hand grip was taken as index of response to hand grip test. The value of more than $15 \mathrm{~mm} \mathrm{Hg}$ rise in diastolic BP was taken as normal response, $11-15 \mathrm{~mm} \mathrm{Hg}$ as borderline and $10 \mathrm{~mm} \mathrm{Hg}$ or less as abnormal indicating sympathetic insufficiency. ${ }^{[24]}$

\section{Result}

50 individuals were include in this study which were grouped into Study group (Group - A) and Control group (Group - B). Group A consisted of 25 individuals who were diagnosed with rheumatoid arthritis on basis of criteria developed by American College of Rheumatology. Group - B consisted of 25 healthy individuals not on any medication as to explain normal changes. The demographic profile by their age and sex was recorded.

Table: 1Showing Difference in group I and group II

\begin{tabular}{|l|c|c|c|c|c|}
\hline & Mean HR+SD & $\begin{array}{c}\text { Mean 30:15 } \\
\text { Ratio + SD }\end{array}$ & $\begin{array}{c}\text { Mean S/L } \\
\text { Ratio + SD }\end{array}$ & $\begin{array}{c}\text { Mean Exp/Insp } \\
\text { Ratio + SD }\end{array}$ & $\begin{array}{c}\text { Mean Valsalva Ratio } \\
+ \text { SD }\end{array}$ \\
\hline Group A & $75.5 \pm 9.1$ & $1.2 \pm 0.2$ & $1 \pm 0.1$ & $1.2 \pm 0.1$ & $1.9 \pm 0.6$ \\
\hline Group B & $72.8 \pm 6.8$ & $1.1 \pm 0.1$ & $1.1 \pm 0.1$ & $1.3 \pm 0.1$ & $1.1 \pm 0.2$ \\
\hline P value & $>0.01(\mathrm{NS})$ & $>0.01(\mathrm{NS})$ & $<0.001(\mathrm{HS})$ & $<0.001(\mathrm{HS})$ & $>0.01(\mathrm{NS})$ \\
\hline
\end{tabular}

HR-Heart Rate, S/L-Standing/Lying, Exp/Insp-Expiration/Inspiration, S- Significant, HS- Highly Significant, NS- Not Significant

Table: 2 showing SBP, DBP in both groups

\begin{tabular}{|l|c|c|c|c|c|c|}
\hline & $\begin{array}{c}\text { Mean \% change } \\
\text { in SBP from lying } \\
\text { to standing } \\
\text { position }\end{array}$ & $\begin{array}{c}\text { Mean \% change } \\
\text { in DBP from } \\
\text { lying to standing } \\
\text { position }\end{array}$ & $\begin{array}{c}\text { Mean \% change } \\
\text { in SBP from } \\
\text { resting to after } \\
\text { hand grip test }\end{array}$ & $\begin{array}{c}\text { Mean \% change in } \\
\text { DBP from resting } \\
\text { to after hand grip } \\
\text { test }\end{array}$ & $\begin{array}{c}\text { Mean \% change } \\
\text { in SBP from } \\
\text { resting to } \\
\text { valsalva }\end{array}$ & $\begin{array}{c}\text { Mean \% change } \\
\text { in DBP from } \\
\text { resting to } \\
\text { valsalva }\end{array}$ \\
\hline Group A & $4.4 \pm 2.8$ & $2.2 \pm 3.1$ & $8.6 \pm 5.7$ & $9.0 \pm 5.6$ & $15.6 \pm 14.2$ & $15.5 \pm 11.7$ \\
\hline Group B & $5.01 \pm 3.4$ & $5.6 \pm 2.1$ & $11.2 \pm 6.6$ & $13.3 \pm 6.7$ & $14.4 \pm 5.2$ & $12.0 \pm 2.6$ \\
\hline P value & $>0.01(\mathrm{NS})$ & $\leq 0.01(\mathrm{~S})$ & $>0.01(\mathrm{NS})$ & $\leq 0.01(\mathrm{~S})$ & $>0.01(\mathrm{NS})$ & $>0.01(\mathrm{NS})$ \\
\hline
\end{tabular}

DBP-Diastolic Blood Pressure, SBP-Systolic Blood Pressure, S- Significant, HS- Highly Significant, NS- Not Significant 


\section{International Journal of Innovative Research in Medical Science (IJIRMS) Volume 03 Issue 12 Dec 2018, ISSN: 2455-8737, Imp. Factor - 4.102 Available online at - www. ijirms.in}

\section{Discussion}

The study between series of patients and the controls showed significant difference for both sympathetic \& parasympathetic autonomic function tests. patients with rheumatoid arthritis and systemic lupus erythematosus has been reported as Autonomic dysfunction. for autonomic dysfunction An immune component can also be responsible. ${ }^{[2]}$ Evaluation of the cardiac functions were done by six non-invasive standardized tests which consisted of 30:15 ratio, expiration / inspiration ratio, standing / lying ratio , valsalva ratio, blood pressure response to standing, blood pressure response to hand grip test and valsalva maneuver. These tests evaluated the parasympathetic and sympathetic ANS division. by using unpaired t-test the results of tests were compared with control.

This study shows expiration to inspiration ratio $(\mathrm{p}<0.01)$, standing to lying ratio $(p<0.001)$, both indicative of parasympathetic function were significantly less as compared to control. In this study also shows decrease indicated an impaired vagal function in group. The 30:15 ratio and valsalva maneuver demonstrated a less decrease but was non-significant statistically in the patients with Rheumatoid Arthritis as compared to control ( $p>0.05)$ as shown in table no 1 .

On standing the blood pressure response the change in diastolic blood pressure was significantly $(\mathrm{P}<0.01)$ lower in groups $\mathrm{A}$ as compared to control which is shown in table no 2 . This result is indicative decreased peripheral resistance that leads to decrease in percentage of change diastolic blood pressure and hypofunctional sympathetic ANS leading to unaltered.

In this study, heart rate variation to 30:15 ratio, Valsalva ratio and deep breathing were found low in patients as compared to control group and the ' $p$ ' values were found almost about less significant, which is almost similar to the findings of different studies as Geenen et al., Toussirot et al., ${ }^{[25]}$ studies of Bekkelund et al., ${ }^{[26]}$ and Piha et al found no CVS ANS abnormality.

\section{Conclusion}

In summary, study confirmed cardiac autonomic nervous system dysfunction (both sympathetic and parasympathetic) occurs in Rheumatoid arthritis when compared to control. Therefore cardiovascular autonomic function tests in routine clinical examination helpful in early detection of autonomic dysfunction in this disease. Further comprehensive information are useful about autonomic function may be extracted from global evaluation of all tests performed. Therefore testing of autonomic function may be the part of routine clinical evaluation in RA to reduce the cardiovascular autonomic morbidity.

\section{References}

[1] Arnett F C Edworthy S M, Bloch D A, et al. The American Rheumatoid Association 1987 revised criteria for the classification of rheumatoid arthritis. Arthritis Rheum. 1998; 31: 315-24

[2] Bax M, van Heemst J, Huizinga TW, Toes RE. Genetics of RA: what have we learned?Immunogenetics.2011; 23:459-66
[3] Firestein G. Evolving concepts of rheumatoid arthritis. Nature 2003;423:356-61.

[4] Prete M, Racanelli V, Digiglio L, Vacca A, Dammacco F, Perosa F. Extra-articular manifestations of rheumatoid arthritis: an update. Autoimmun Rev 2011;11:123-31.

[5] Deal CL, Meenan RF, Goldenb erg DL.The clinical features of elderlyonsetrheumatoid arthritis. A comparisonwith younger-onset disease of similarduration. Arthritis and Rheumatism 1985; 28(9): 9 87-994.

[6] Huizinga T.W.J, Mil A. A quantitative approach to early RA. Bull NYU Hosp Jt Dis. 2011; 69(2): 116-21.

[7] Rosenbaum R. Neuromuscular complications of connective tissue diseases. Muscle Nerve 2001;24:15469.

[8] Hsitsma E, Reulen J, de Baets M, Drent M, Spaans F, Faber C. Small fiber neuropathy: a common and important clinical disorder. J Neurol Sci 2004;227:11930 .

[9] James P, Dyek B, Ted M Burns, Gregory A. Schauplin: Vasculitic Neuropathies. NeurolClin2007; 25: 89-113.

[10] Dekkers JC, Geenen R, Godaert GL, Bijlsma JW, van Doornen LJ. Elevated sympathetic nervous system activity in patients with recently diagnosed rheumatoid arthritis with active disease. Clin Exp Rheumatol. 2004; 22:63-70.

[11] Wislowska M, Sypula S, Kowalik I. Echocardiographic findings, 24-hour electrocardiographic Holter monitoring in patients with rheumatoid arthritis according to Steinbrocker's criteria, functional index, value of Waaler-Rose titre and duration of disease. Clin Rheumatol 1998; 17: 369-77.

[12] Goodson N, Marks J, Lunt M, Symmons D. Cardiovascular admissions and mortality in an inception cohort of patients with rheumatoid arthritis with onset in the 1980s and 1990s. Ann Rheum Dis 2005; 64: 1595601.

[13] Maradit-Kremers H, Nicola PJ, Crowson CS, Ballman $\mathrm{KV}$, Gabriel SE. Cardiovascular death in rheumatoid arthritis: a populationbased study. Arthritis Rheum 2005; 52: 722-32.

[14] Louthrenoo W, Ruttanaumpawan P, Aramrattana A, Sukitawut W. Cardiovascular autonomic nervous system dysfunction in patients with rheumatoid arthritis and systemic lupus erythematosus. QJM 1999 Feb;92(2):97102.

[15] Arnett F C Edworthy S M, Bloch D A, et al. The American Rheumatoid Association 1987 revised criteria for the classification of rheumatoid arthritis. Arthritis Rheum. 1998; 31: 315-24

[16] Ewing D J, Campell I W, Murray A, Neilson J M, Clarkes B F. Immediate heart rate response to standing simple test for autonomic neuropathy in diabetes. $\mathrm{Br}$ Med J 1978; 1: 145- 147.

[17] Ahuja M V, Kumar Ramesh. Basal autonomic functions in males and females. Indian J PhysiolPharmacol. 1999; 43(4): 521- 522

[18] Jain A K. Manual of practical physiology for MBBS. 1st Edition. New Delhi, Arya Publications 2003: 248-252. 
[19] Sandroni P. Testing the autonomic nervous system. Technical Corner from IASP (International Association for Study of Paid) Newsletter. 1998 Nov/Dec. 1-10.

[20] Marya R K. Medical Physiology. 2nd edition. New Delhi: CBS; 2003: 302-303.

[21] Raclene E Maser. Autonomic neuropathy: Patients care. Diabetes Spectrum. 1998: 11(4): 224-227.

[22] Jain A K. Manual of Practical physiology for MBBS. 2nd Edition. New Delhi: Arya Publications; 2007: 283284

[23] Ghai C L. A textbook of practical physiology. 7th Edition. New Delhi: Jaypee Brothers; 2007: 245.
[24] Saraswathi PV, Neelambikai N, Mahesh A, GovindarajanK.Indian J Physiol Pharmacol.2013 JanMarch;57(1):23-30

[25] Toussirot E, Serratrice G, Valentin P. Autonomic nervous system involvement in rheumatoid arthritis. 50 Cases. J Rheumatol 1993; 20: 1508-14.

[26] Bekkelund SI, Jorde R, Husby G, Mellgren SI. Autonomic nervous system function in rheumatoid arthritis. A controlled study. J.Rheumatol. 1996 Oct;23(10):1710-1714 